\title{
ADSORPTION OF PHENOL COMPOUNDS BY ACTIVATED CARBON FORMED DURING CARBONIZATION OF BROWN COAL WITH POTASSIUM HYDROXIDE
}

(C) Ju.V. Tamarkina, PhD in Chemical Sciences, I.B. Frolova, PhD in Chemical Sciences, O.O. Velichko, V.O. Kucherenko, Doctor of Chemical Sciences (L.M. Litvinenko Institute of PhysicalOrganic Chemistry and Coal Chemistry of the National Academy of Sciences of Ukraine, 02160, Kyiv, Kharkiv Highway St., 50, Ukraine)

The aim of the work is to evaluate the adsorption capacity of activated carbons (ACs) from brown coal in relation to phenol $(\mathrm{Ph})$ and 4-chlorophenol $(\mathrm{CPh})$ and the influence of the ACs formation temperature under carbonization with potassium hydroxide on capacities.

The samples of ACs were prepared by heating with $\mathrm{KOH}(1 \mathrm{~g} / \mathrm{g}, 1 \mathrm{~h})$ at a given temperature in the range of $t=400-800^{\circ} \mathrm{C}$ and marked as $\mathrm{AC}(\mathrm{t})$. The ACs porosity characteristics were determined by low-temperature (77 K) adsorption - desorption nitrogen isotherms (Micromeritics ASAP 2020) calculated by the 2D-NLDFT method. They are as follows: total pore volume $V_{t}\left(\mathrm{~cm}^{3} / \mathrm{g}\right)$, specific surface area $S\left(\mathrm{~m}^{2} / \mathrm{g}\right)$, volume $\left(V_{m i}\right)$ and surface $\left(S_{m i}\right)$ of micropores, volume $\left(V_{1 n m}\right)$ and surface $\left(S_{1 n m}\right)$ of subnanopores, the total surface of meso- and macropores $S_{m e+m a}$. The adsorption of phenol and 4-chlorophenol was determined at equilibrium concentrations in aqueous solutions $\leq 5 \mathrm{mmol} / \mathrm{l}\left(25^{\circ} \mathrm{C}\right)$.

The alkaline carbonization temperature of brown coal was found to be a key factor in the formation of micro- and subnanopores, the growth of the AC specific surface area (from $12.8 \mathrm{~m}^{2} / \mathrm{g}$ to $1142 \mathrm{~m}^{2} / \mathrm{g}$ ) and adsorption activity against phenolic compounds. Its increase to $800^{\circ} \mathrm{C}$ causes an exponential increase in the AC adsorption capacity in 8.7 times (Ph) and 6.7 times ( $\mathrm{CPh}$ ), which is proportional to the concentration of surface adsorption centers (AdCs). The values of the effective activation energy of forming AdCs being active in relation to adsorbates were determined as $29.5 \mathrm{~kJ} / \mathrm{mol}(\mathrm{Ph})$ and 31.5 $\mathrm{kJ} / \mathrm{mol}(\mathrm{CPh})$. The kinetics of Ph and CPh absorption was found to obey the pseudosecond-order model, and the adsorption rate is limited by the interaction of the adsorbate molecules with the AdCs. Adsorption isotherms at equilibrium concentrations $\leq 5 \mathrm{mmol} / \mathrm{l}$ are approximated by the Langmuir model $\left(R_{2} \geq 0.994\right)$. Compared with $\mathrm{Ph}$, the degree of $\mathrm{CPh}$ extraction is much higher, which is a consequence of its stronger connection with the AC surface. The specific adsorption capacity for Ph and CPh shows a sharp decrease (10-16 times) with increasing carbonization temperature from $400^{\circ} \mathrm{C}$ to $550{ }^{\circ} \mathrm{C}$ and a weak temperature dependence at 550-800 ${ }^{\circ} \mathrm{C}$. In this range, ACs are formed with similar concentrations of AdCs, but different for various phenolic compounds. Adsorption on brown coal ACs was postulated to include $\pi$ - $\pi$ interaction, formation of electron-donor-acceptor complexes and formation of hydrogen bonds, but their contributions depend on adsorbate nature and they change while increasing alkaline carbonization temperature.

Keywords: brown coal, alkaline carbonization, activated carbon, porosity, adsorption, phenol, 4-chlorophenol.

Corresponding author Tamarkina Ju.V., e-mail: Tamarkina@nas.gov.ua 